\title{
Bronchial nitric oxide is related to symptom relief during fluticasone treatment in COPD
}

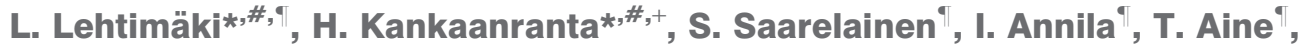 \\ R. Nieminen*,\# and E. Moilanen*,\#
}

ABSTRACT: High levels of exhaled nitric oxide (NO) predict favourable response to inhaled corticosteroids in asthma, but the ability of exhaled NO or inflammatory markers in exhaled breath condensate $(E B C)$ to predict steroid responsiveness in chronic obstructive pulmonary disease (COPD) is not known.

We measured alveolar and bronchial NO output, levels of leukotriene $\mathrm{B}_{4}\left(\mathrm{LTB}_{4}\right)$, cysteinyl leukotrienes (cysLTs) and 8-isoprostane in EBC, spirometry, body plethysmography and symptoms in 40 subjects with COPD before and after 4 weeks of treatment with inhaled fluticasone $(500 \mu \mathrm{g}$ b.i.d.).

Five subjects (12.5\%) with COPD had significant improvement in lung function during fluticasone treatment, whereas 20 subjects $(50 \%)$ had significant decrease in symptoms. High baseline bronchial NO flux was associated with higher increase in forced expiratory volume in $1 \mathrm{~s}$ to forced vital capacity ratio $(r=0.334, p=0.038)$ and more symptom relief $(r=-0.317, p=0.049)$ during the treatment. Baseline EBC levels of $\mathrm{LTB}_{4}$, cysLTs or 8-isoprostane were not related to response to fluticasone treatment. Inhaled fluticasone decreased bronchial NO flux but not alveolar NO concentration or markers in EBC.

High levels of bronchial NO flux are related to symptom relief and improvement of airway obstruction during treatment with inhaled fluticasone in COPD. Markers of inflammation or oxidative stress in EBC are not related to steroid responsiveness in COPD.

KEYWORDS: Chronic obstructive pulmonary disease, corticosteroids, 8-isoprostane, leukotrienes, nitric oxide, spirometry

hronic obstructive pulmonary disease (COPD) is characterised by chronic bronchitis and emphysema causing an airflow obstruction, which, by definition, is not fully reversible [1]. High numbers of neutrophils and macrophages are typical of the airway inflammation in COPD, but eosinophils are also present in some subjects [2]. As treatment with inhaled corticosteroids (ICS) is usually more efficient in eosinophilic than in neutrophilic airway inflammation, the role of ICS in the treatment of stable COPD is controversial. Treatment with ICS is currently recommended for patients with severe COPD and frequent exacerbations [1]. ICS are less effective in COPD than in asthma, but some subjects with COPD gain from ICS by improvement in their lung function and health status [3]. High levels of markers of eosinophilic inflammation, like exhaled NO concentration [4] and sputum eosinophils [5], predict favourable response to ICS in asthma, and these markers may also be useful in titrating the ICS dose in long-term asthma management $[6,7]$. There are also some studies showing that high levels of sputum eosinophils in COPD predict favourable response to a short course of oral prednisolone [8] or ICS [9, 10], but the role of exhaled NO or inflammatory markers in exhaled breath condensate $(\mathrm{EBC})$ in predicting response to ICS in COPD is not known.

Exhaled NO has usually been measured at a single exhalation flow rate of $50 \mathrm{~mL} \cdot \mathrm{s}^{-1}$ [11]. More information on airway inflammation and its anatomical location can be gained by measuring exhaled $\mathrm{NO}$ at multiple flow rates and calculating alveolar $\mathrm{NO}$ concentration $(\mathrm{CA}, \mathrm{NO})$ and bronchial NO flux $\left(J^{\prime}\right.$ aw,NO) [12-14]. COPD has been associated with decreased [15] or normal $[16,17] J^{\prime}$ aw,NO (NO from central large airways) and increased $[15,16]$ or normal [17] CA,NO (NO from alveoli and small peripheral airways). Varying results are probably explained by differences in smoking status and heterogeneity in the inflammatory status and the use of ICS. Furthermore, $\mathrm{CA}, \mathrm{NO}$ has been shown to correlate negatively with forced expiratory volume in $1 \mathrm{~s}$ (FEV1)
AFFILIATIONS

*The Immunopharmacology

Research Group, Medical School,

University of Tampere,

${ }^{\#}$ The Science Centre, Tampere

University Hospital,

'Dept of Respiratory Medicine,

Tampere University Hospital,

Tampere, and

+Dept of Respiratory Medicine,

Seinäjoki Central Hospital, Seinäjoki,

Finland.

CORRESPONDENCE

L. Lehtimäki

The Immunopharmacology Research Group

Medical School

FIN-33014 University of Tampere

Finland

E-mail: lauri.lehtimaki@uta.fi

Received:

Nov 232008

Accepted after revision:

June 242009

First published online:

July 022009

European Respiratory Journal

Print ISSN 0903-1936

Online ISSN 1399-3003 
in COPD [15], which is in line with the small airways being the main site of airflow limitation in COPD.

Airway inflammation also can be noninvasively assessed by collecting $\mathrm{EBC}$ and analysing levels of biomarkers in the condensate. Leukotriene $\mathrm{B}_{4}\left(\mathrm{LTB}_{4}\right)$ is a chemotactic factor for neutrophils [18], and increased levels of $\mathrm{LTB}_{4}$ have been found in states of neutrophilic airway inflammation like COPD [19, 20]. Cysteinyl leukotrienes (cysLTs) have been associated with eosinophilic inflammation [21], and increased cysLT concentrations in EBC have been found in asthmatic subjects [19, 22]. The effect of oxidative stress can be assessed by measuring the EBC level of 8-isoprostane, a marker of lipid peroxidation [23].

In cross-sectional studies, ICS have been reported to have no effect on EBC levels of $\mathrm{LTB}_{4}$ [24], and to slightly decrease [15] or to have no effect [17] on bronchial NO output. However, there are no interventional studies on the effect of ICS on noninvasive markers of pulmonary inflammation, or on the ability of these markers to predict steroid responsiveness in COPD. The aim of the current study was to assess the effect of ICS on $J^{\prime}$ aw,NO and CA,NO, and on the levels of $\mathrm{LTB}_{4}$, cysLTs and 8-isoprostane in EBC in patients with COPD, and to study if these markers can predict the individual effect of ICS on lung function and symptoms in COPD.

\section{METHODS}

\section{Subjects}

Patients with COPD were recruited among subjects referred from primary care for diagnostic assessment to the Department of Respiratory Medicine at Tampere University Hospital, Tampere, Finland. The inclusion criteria were symptoms compatible with COPD (cough, sputum production and chest tightness), post-bronchodilator FEV1/forced vital capacity $(\mathrm{FVC})$ ratio $<0.7$, smoking history $\geqslant 20$ pack-yrs, and emphysema on high-resolution computed tomography (HRCT) of the lungs. Exclusion criteria were history of asthma, significant diurnal variation in home peak expiratory flow monitoring, any other pulmonary disease, arterial oxygen tension $<8.0 \mathrm{kPa}$ or diabetes. Only reliever medication with short-acting $\beta_{2}$-agonists was allowed. Possible ICS or theophylline were withdrawn for at least 4 weeks before the first measurements. The study was approved by the ethics committee of Tampere University Hospital and all subjects gave their written informed consent.

\section{Study protocol}

Spirometry (Vmax 20C; SensorMedics, Yorba Linda, CA, USA) and body plethysmography (Autobox 6200, SensorMedics) were measured before and after inhaled salbutamol $(400 \mu \mathrm{g})$. 2-week home peak expiratory flow monitoring was conducted to rule out asthma-like diurnal variation in airway obstruction. HRCT of the lungs was scanned (Siemens Somatom Plus 4; Siemens Medical, Erlangen, Germany). In addition, exhaled $\mathrm{NO}$ was measured, EBC was collected, and the subjects filled in a symptom questionnaire. The same measurements excluding HRCT were repeated after 4 weeks of treatment with inhaled fluticasone propionate (Flixotide Diskus $500 \mu \mathrm{g}$ b.i.d.; GlaxoSmithKline, Ware, UK).

\section{Exhaled NO}

Exhaled NO was measured with a Sievers NOA 280 analyser (Sievers Instruments, Boulder, CO, USA) at exhalation flow rates of $50,100,200$ and $300 \mathrm{~mL} \cdot \mathrm{s}^{-1}$. The desired exhalation flow rates were achieved by letting the patients exhale through a mass flow meter connected to a computer-controlled adjustable flow restrictor that kept the flow rate steady at the desired level $[25,26]$.

CA,NO and J'aw,NO were calculated with the linear method as previously described, using exhalation flow rates of 100, 200 and $300 \mathrm{~mL} \cdot \mathrm{s}^{-1}[12,27]$. Exhaled NO output (exhaled NO concentration multiplied by exhalation flow rate) was plotted against exhalation flow rate and a linear regression was set (Microsoft Excel). Slope and intercept of the regression line are approximates of $\mathrm{CA}, \mathrm{NO}$ and $J^{\prime}$ aw,NO respectively.

Axial backward diffusion of NO from bronchial compartment to alveoli may cause falsely high CA,NO and falsely low J'aw,NO especially in subjects with high $J^{\prime}$ aw,NO. CA,NO and J'aw,NO adjusted for trumpet shape airways and axial diffusion (CA,NO(TMAD) and J'aw,NO(TMAD), respectively) were calculated according to the equations 1 and 2 as described by CONDORELLi et al. [28].

$$
\begin{gathered}
\mathrm{CA,NO}(\mathrm{TMAD})(\mathrm{ppb})=\mathrm{CA}, \mathrm{NO}(\mathrm{ppb})-\frac{J^{\prime} \mathrm{aw}, \mathrm{NO}\left(\mathrm{nL} \cdot \mathrm{s}^{-1}\right)}{0.86\left(\mathrm{~L} \cdot \mathrm{s}^{-1}\right)} \\
J^{\prime} \text { aw,NO(TMAD) }\left(\mathrm{nL} \cdot \mathrm{s}^{-1}\right)=J^{\prime} \text { aw,NO }\left(\mathrm{nL} \cdot \mathrm{s}^{-1}\right) \times 1.7
\end{gathered}
$$

The difference between $\mathrm{CA}, \mathrm{NO}$ and $\mathrm{CA}, \mathrm{NO}(\mathrm{TMAD})$ is dependent on individual $J^{\prime}$ aw, NO and there may, therefore, be differences in result profiles between $\mathrm{CA}, \mathrm{NO}$ and $\mathrm{CA}, \mathrm{NO}(\mathrm{TMAD})$. On the contrary, J'aw,NO(TMAD) is precisely 1.7 times higher than $J$ 'aw,NO in every subject; therefore, all the correlations to other markers or treatment changes in J'aw,NO and J'aw,NO(TMAD) are exactly the same, but the absolute values are 1.7 times higher in $J^{\prime}$ aw,NO(TMAD).

\section{Exhaled breath condensate}

EBC was collected during 15 min of tidal breathing with Ecoscreen condenser (Ecoscreen; Jaeger, Hoechberg, Germany) while wearing nose clips. The samples were stored at $-70^{\circ} \mathrm{C}$ until assayed. $\mathrm{LTB}_{4}, 8$-isoprostane and cysLT concentrations in the condensates were measured by immunoassay with a detection limit of $2 \mathrm{pg} \cdot \mathrm{mL}^{-1}$ (Cayman Chemical Company, Ann Arbor, MI, USA).

\section{Symptom scoring}

The subjects filled in a Finnish translation of the St George's Respiratory Questionnaire (SGRQ) containing questions and scoring on three aspects of the disease (symptom frequency and severity, activities that cause or are limited by breathlessness, and the impact of the disease on social functioning with psychological disturbances resulting from the disease) and a total score. Each score ranges from 0 to 100, with higher score meaning worse disease. A change of $\geqslant 4$ points is considered as a significant change in the disease state [29].

\section{Statistics}

Based on power calculations, 40 patients were needed for the final analysis to give the study a power of $\sim 90 \%$ to detect a change of 0.5 standard deviations in each parameter during the fluticasone treatment (effect size 0.5) with an $\alpha$ of 0.05 . Distributions of the NO parameters and inflammatory markers in breath condensate were non-normal, whereas lung function parameters and symptom scores were normally distributed 
(Shapiro-Wilk test). Ex-smokers and current smokers were compared using t-test for normal data, Mann-Whitney U-test for non-normal data and Fisher's exact test for binary variables. Changes in parameters during the treatment were analysed using paired t-test for normal data and Wilcoxon signed rank test for non-normal data. Correlations between baseline inflammatory markers and changes in lung function or symptoms during the treatment were analysed with Spearman's rank correlation. SPSS 12.0.1 software (SPSS Inc., Chicago, IL, USA) was used for statistical analysis. Results are given as mean \pm SEM for normally distributed data and as median (interquartile range) for non-normal data. p-values $<0.05$ were considered as statistically significant.

\section{RESULTS}

To obtain 40 patients for the final analysis, 55 patients needed to be recruited. Four subjects were excluded due to technical problems in NO measurements, five had an exacerbation during the study period, two subjects were not willing to continue in the study, and timing of the study medication and follow-up was wrong in four subjects. The 40 subjects included in the analysis had NO results of good quality and there was high linearity $(r \geqslant 0.96)$ between $\mathrm{NO}$ output and flow rate in the range $100-300 \mathrm{~mL} \cdot \mathrm{s}^{-1}$.

The majority $(n=30)$ of the patients had moderate COPD (stage II) according to the Global Initiative for Chronic Obstructive Lung Disease (GOLD) criteria [1], three subjects had stage I, six subjects had stage III, and one subject had stage IV COPD. None of the subjects had signs of interstitial lung disease on HRCT scans.

Spirometry and body plethysmography, NO parameters and inflammatory markers in EBC according to the current smoking status are presented in table 1. Current smokers had slightly better lung function, and lower fractional exhaled NO concentration at exhalation flow rate of $0.05 \mathrm{~L} \cdot \mathrm{s}^{-1}\left(\mathrm{FeNO}_{0.05}\right)$ and $J^{\prime}$ aw,NO compared with ex-smokers. There were no differences in other NO parameters or inflammatory markers in breath condensate between current and ex-smokers. 17 subjects had reversibility in FEV $1 \geqslant 12 \%$ and $200 \mathrm{~mL}$ after salbutamol inhalation, but there were no differences in baseline pulmonary function or any of the inflammatory measures between responders and nonresponders to salbutamol (data not shown).

Five out of 40 subjects used ICS during the enrolment, and ICS were stopped for 4 weeks before entering the study. EBC levels of 8-isoprostane (16.1 (10.8-19.1) versus 9.1 (7.3-14.1) $\mathrm{pg} \cdot \mathrm{mL}^{-1}$; $\mathrm{p}=0.024)$ and CysLTs (30.0 (7.4-58.7) versus $2.8(1.0-12.7)$ $\left.\mathrm{pg} \cdot \mathrm{mL}^{-1} ; \mathrm{p}=0.040\right)$ were higher in those who used ICS at the enrolment, but there were no differences in NO parameters, lung function or symptoms between those who used ICS at enrolment and those who did not.

Levels of inflammatory markers, spirometry and body plethysmography and symptom scores before and after fluticasone treatment are presented in table 2. Fluticasone

\begin{tabular}{|c|c|c|c|}
\hline & Smokers & Ex-smokers & p-value \\
\hline Subjects $\mathrm{n}$ & 29 & 11 & \\
\hline Males/females $n$ & $18 / 11$ & $9 / 2$ & $0.286^{\#}$ \\
\hline Post-bronchodilator FEV 1 \% pred & $64.6 \pm 2.7$ & $53.3 \pm 4.8$ & $0.037^{\circ}$ \\
\hline RV \% pred & $150.7 \pm 6.7$ & $164.5 \pm 17.7$ & $0.481^{\circ}$ \\
\hline Raw \% pred & $190.5 \pm 10.4$ & $273.6 \pm 44.5$ & $0.096^{\circ}$ \\
\hline TL,Co \% pred & $54.8 \pm 2.1$ & $50.3 \pm 4.1$ & $0.309^{\bullet}$ \\
\hline $\mathrm{FeNO}_{0.05} \mathrm{ppb}$ & $8.8(5.1-13.5)$ & $16.2(11.5-19.1)$ & $0.025^{+}$ \\
\hline $\mathrm{FeNO}_{0.1} \mathrm{ppb}$ & $5.2(3.8-8.2)$ & $8.1(5.8-10.3)$ & $0.052^{+}$ \\
\hline CA,NO ppb & $3.0(2.3-3.8)$ & $3.3(2.4-3.6)$ & $0.680^{+}$ \\
\hline $\mathrm{CA}_{\mathrm{A}, \mathrm{NO}}(\mathrm{TMAD}) \mathrm{ppb}$ & $2.8(1.9-3.4)$ & $2.5(1.5-3.6)$ & $0.899^{+}$ \\
\hline $\mathrm{EBC} \mathrm{LTB}_{4} \mathrm{pg} \cdot \mathrm{mL}^{-1}$ & $6.7(5.0-9.0)$ & $6.4(4.0-12.3)$ & $1.000^{+}$ \\
\hline EBC cysLT pg $\cdot \mathrm{mL}^{-1}$ & $8.4(1.0-13.9)$ & $6.6(1.0-12.8)$ & $0.824^{+}$ \\
\hline EBC 8-isoprostane $\mathrm{pg} \cdot \mathrm{mL}^{-1}$ & $9.3(7.3-14.2)$ & $10.3(8.8-17.3)$ & $0.280^{+}$ \\
\hline
\end{tabular}

Data are presented as mean \pm SEM or median (interquartile range), unless otherwise stated. FEV1: forced expiratory volume in $1 \mathrm{~s} ; \%$ pred: \% predicted; FVC: forced vital capacity; FEF $75 \%$ : forced expiratory flow when $75 \%$ of vital capacity is exhaled; RV: residual volume; Raw: airway resistance; $T L, C O$ : pulmonary transfer factor for carbon monoxide; FeNOx: fractional exhaled NO concentration at exhalation flow rate of $x \mathrm{~L} \cdot \mathrm{S}^{-1}$; J'aw,NO: bronchial NO flux; J'aw,NO(TMAD): bronchial NO flux adjusted for trumpet shape airways and axial diffusion; CA,NO: alveolar NO concentration; CA,NO(TMAD): alveolar NO concentration adjusted for trumpet shape airways and axial diffusion; $\mathrm{LTB}_{4}$ : leukotriene $\mathrm{B}_{4}$; cysLT: cysteinyl leukotriene. ${ }^{\#}$ : Fisher's exact test for sex-distribution between smokers and ex-smokers; " smokers; ${ }^{+}$: Mann-Whitney U-test between smokers and ex-smokers. Values in bold are statistically significant. 
treatment decreased $J^{\prime}$ aw, $\mathrm{NO}$ and $\mathrm{FeNO}_{0.05}$ but had no effect on CA,NO. There were no changes in breath condensate levels of $\mathrm{LTB}_{4}$, cysLTs or 8-isoprostane.

Fluticasone treatment decreased residual volume but had no other effects on mean pulmonary function (table 2). However, five out of the 40 patients $(12.5 \%)$ had improvement in FEV1 $\geqslant 12 \%$ and $200 \mathrm{~mL}$ during the fluticasone treatment. The relative number of responders tended to be higher in ex-smokers (three out of $11(27.3 \%)$ ) than in current smokers (two out of $29(6.9 \%)$; $\mathrm{p}=0.117$ ). Baseline $J$ 'aw,NO correlated positively with the change in post-bronchodilator FEV1/FVC $(r=0.334, p=0.038$; fig. 1$)$, and this correlation was even stronger in ex-smokers $(r=0.621$, $\mathrm{p}=0.042)$, but nonsignificant in current smokers $(r=0.152$, $\mathrm{p}=0.432$ ). Baseline CA,NO correlated negatively with the relative change in forced expiratory flow when $75 \%$ of vital capacity is exhaled (FEF75\%) $(\mathrm{r}=-0.340, \mathrm{p}=0.037$; fig. 1$)$, whereas baseline $\mathrm{CA}, \mathrm{NO}(\mathrm{TMAD})$ correlated negatively with the relative change in FEF75\% $(r=-0.395, p=0.014)$ and positively with the relative change in functional residual capacity $(F R C)(r=0.341, p=0.036)$. Thus, low baseline $\mathrm{CA}, \mathrm{NO}$ and $\mathrm{CA}, \mathrm{NO}(\mathrm{TMAD})$ were associated with better functional outcome (increase in FEF75\% and decrease in FRC). There were no other significant correlations between baseline inflammatory markers and change in lung function.

Fluticasone treatment decreased symptoms measured by SGRQ (table 2), and 20 patients (50\%) had significant decrease in symptoms defined as decrease in SGRQ total score of $\geqslant 4$ points. The relative number of responders was similar in exsmokers (six out of $11(54.5 \%)$ ) and current smokers (14 out of $29(48.3 \%) ; \mathrm{p}=1.000)$. Baseline $\mathrm{FeNO}_{0.05}(\mathrm{r}=-0.373, \mathrm{p}=0.013)$ and $J^{\prime}$ aw, NO $(\mathrm{r}=-0.317, \mathrm{p}=0.049)$ correlated negatively with the change in SGRQ total score during fluticasone treatment, i.e. subjects with high bronchial NO output had more pronounced decrease in symptoms during the treatment. These correlations were similar in subgroups of ex-smokers and current smokers. Baseline $\mathrm{FeNO}_{0.05}$ and $J^{\prime}$ aw,NO were higher in those patients who gained a decrease of $\geqslant 4$ points in SGRQ total score during fluticasone treatment (fig. 2). Other baseline inflammatory markers were not related to symptom change during the treatment.

\section{DISCUSSION}

In the present study, we found that inhaled fluticasone decreased $J^{\prime}$ aw,NO but had no effect on CA,NO in patients with COPD. Fluticasone improved lung function significantly (increase in FEV1 $\geqslant 12 \%$ and $200 \mathrm{~mL}$ ) in only five out of 40 subjects, but 20 subjects had significant symptom relief. Baseline $J^{\prime}$ aw,NO correlated with increase in post-bronchodilator FEV1/FVC and decrease in symptoms during fluticasone treatment, whereas baseline CA,NO correlated negatively with the change in FEF75\% during the treatment. Levels of 8isoprostane, $\mathrm{LTB}_{4}$ and cysLTs in EBC were not affected by fluticasone treatment, and these markers were not related to fluticasone-induced changes in lung function or symptoms.

The multiple flow rate method is a promising extension of exhaled NO measurement, as it allows separate assessment of NO output in large central airways $\left(J^{\prime}\right.$ aw,NO) and in the peripheral small airways/pulmonary parenchyma (CA,NO) [12-14]. This method has been shown to be suitable for measuring central and peripheral inflammation in airway

TABLE 2 Lung function, NO parameters and inflammatory markers in exhaled breath condensate (EBC) and symptom scores in 40 patients with chronic obstructive pulmonary disease before and after 4 weeks of treatment with inhaled fluticasone

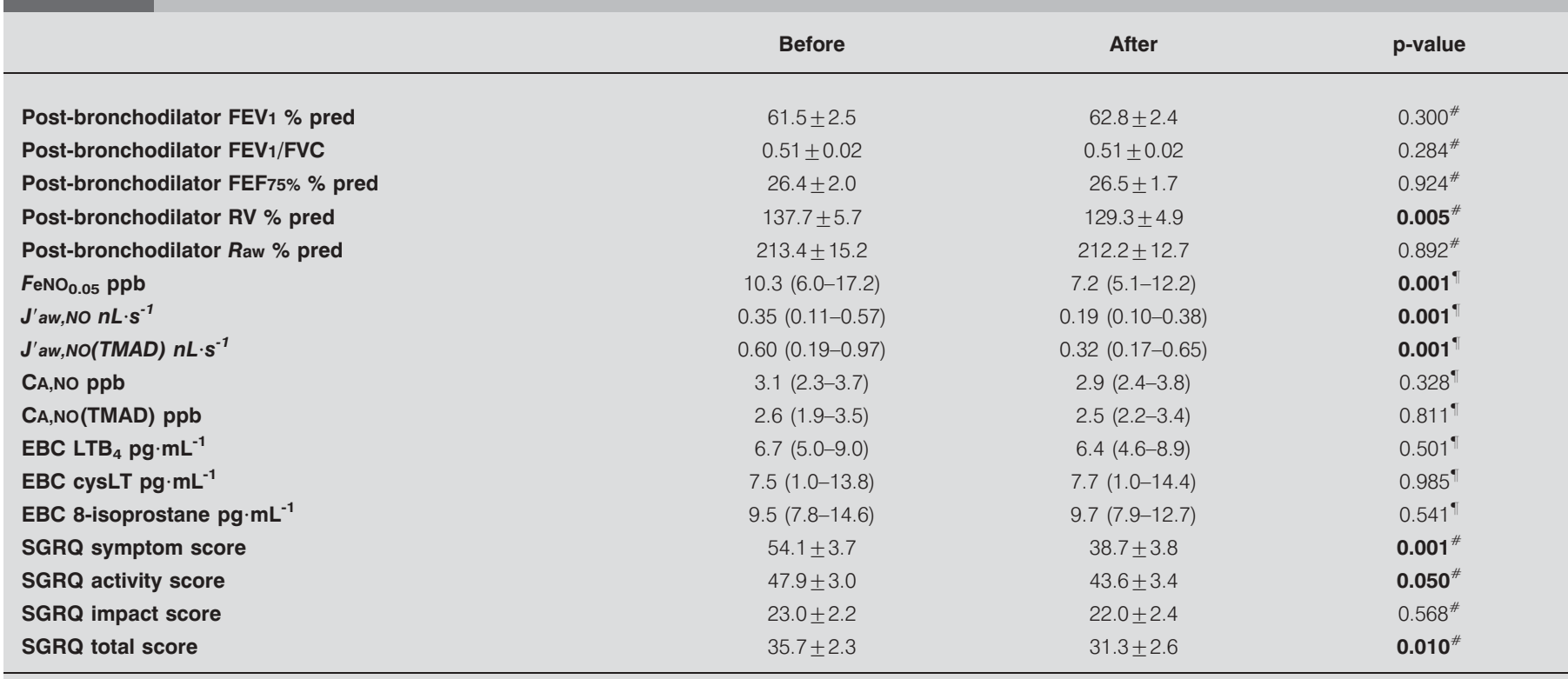

Data are presented as mean \pm SEM or median (interquartile range), unless otherwise stated. FEV1: forced expiratory volume in 1 s; \% pred: \% predicted; FVC: forced vital capacity; FEF75\%: forced expiratory flow when $75 \%$ of vital capacity is exhaled; RV: residual volume; Raw: airway resistance; $F_{e N O}$. 05 : fractional exhaled NO concentration at exhalation flow rate of $0.05 \mathrm{~L} \cdot \mathrm{S}^{-1} ; \mathrm{J}$ 'aw,NO: bronchial NO flux; J'aw,NO(TMAD): bronchial NO flux adjusted for trumpet shape airways and axial diffusion; CA,NO: alveolar

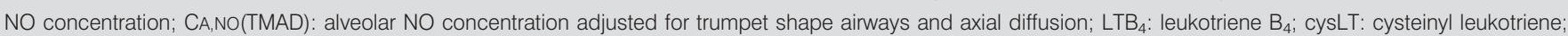
SGRQ: St George's Respiratory Questionnaire. ${ }^{*}$ : paired t-test; ${ }^{\bullet}$ : Wilcoxon's test. Values in bold are statistically significant. 

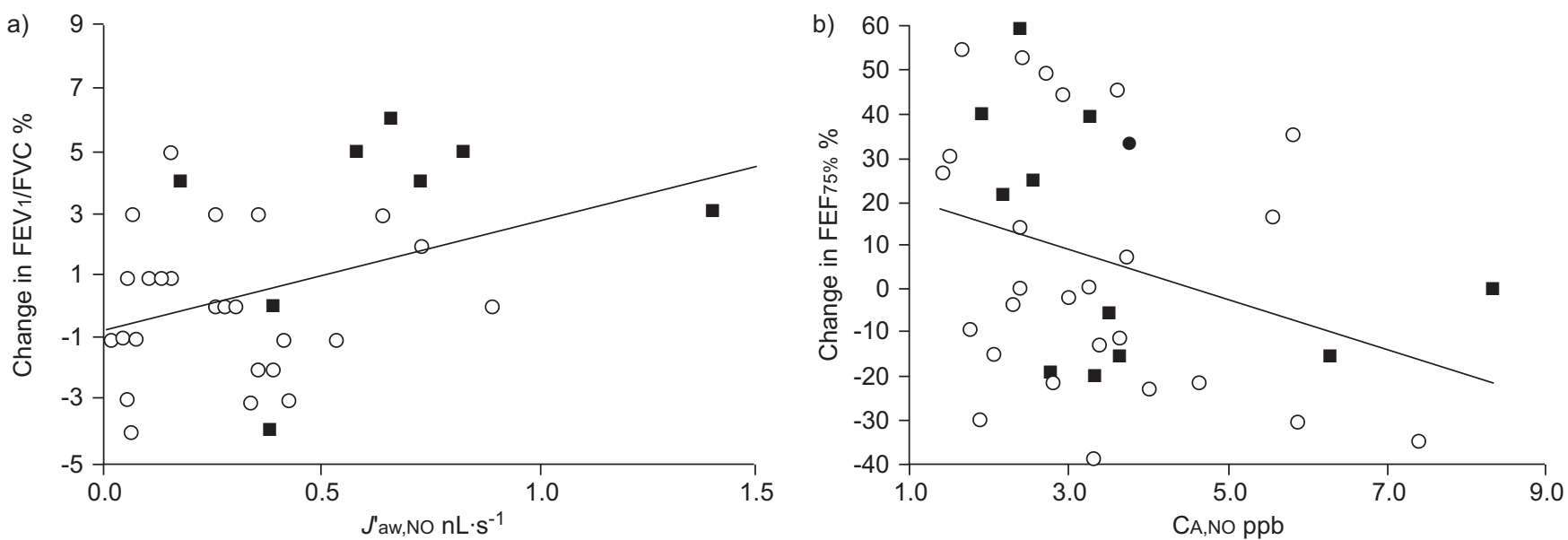

FIGURE 1. a) Baseline bronchial NO flux ( $J^{\prime}$ aw, NO) correlated positively $(r=0.334, p=0.038)$ with the change in post-bronchodilator forced expiratory volume in $1 \mathrm{~s}$ (FEV1)/forced vital capacity (FVC) ratio, whereas b) baseline alveolar NO concentration (CA,NO) correlated negatively $(r=-0.340, p=0.037)$ with the relative change in forced expiratory flow when $75 \%$ of vital capacity is exhaled (FEF $75 \%$ in 40 current smokers $(O)$ and ex-smokers $(\mathbf{D})$ with chronic obstructive pulmonary disease during 4 weeks of treatment with inhaled fluticasone.

diseases and parenchymal diseases [15-17, 25, 27]. A further extension of the model to theoretically simulate the effects of spatial heterogeneity in pulmonary inflammation has recently been introduced [30].

In COPD and asthma, eosinophilic rather than neutrophilic inflammatory activity predicts favourable response to ICS [5, 810]. Nitric oxide output is associated mainly with eosinophilic airway inflammation [31-33], whereas $\mathrm{LTB}_{4}$ (chemotactic factor for neutrophils) and 8-isoprostane (marker of lipid peroxidation) are associated with neutrophilic inflammation [18, 23]. It is, therefore, understandable that NO parameters, but not EBC $\mathrm{LTB}_{4}$ and 8-isoprostane, decreased during fluticasone treatment and were associated with the response of symptoms and lung function to ICS. It might be that indices of neutrophilic

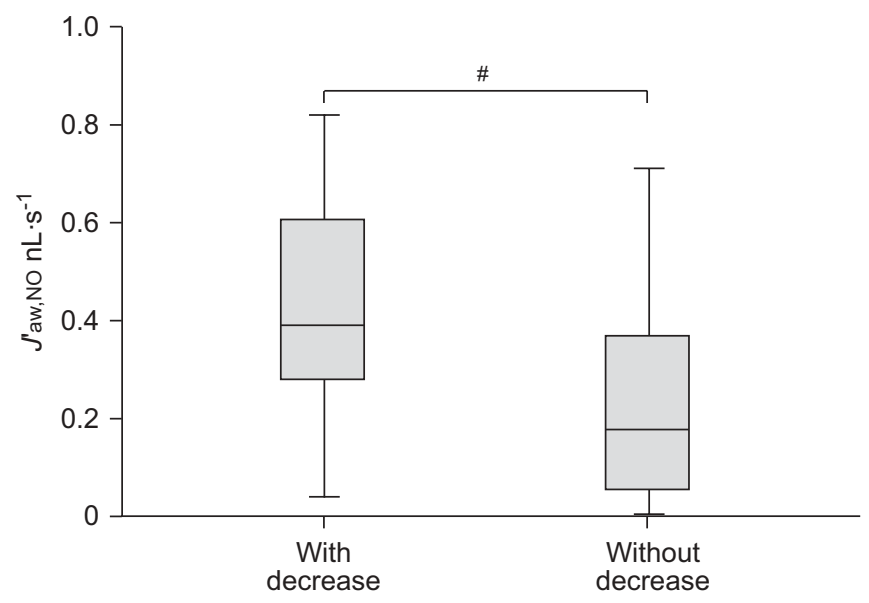

FIGURE 2. Baseline bronchial NO flux (J'aw,NO) in subjects with and without significant decrease in symptoms (decrease of $\geqslant 4$ points in the St George's Respiratory Questionnaire) during 4 weeks of treatment with inhaled fluticasone. Results are plotted as medians and quartiles (whiskers represent the first and fourth quartiles, boxes the second and third quartiles). ${ }^{*}: p=0.016$. inflammatory activity, like $\mathrm{LTB}_{4}$ and 8-isoprostane in EBC, could better predict response to drug treatment specifically aimed to tackle neutrophilic inflammation.

We found that inhaled fluticasone decreased $J^{\prime}$ aw,NO but had no effect on CA,NO. The decrease in bronchial NO output is in line with the effect of fluticasone in asthma [34] and suggests that there is at least some steroid-responsive component in the airway inflammation in these subjects. The decrease in J'aw,NO following fluticasone treatment may be explained by decrease in inflammatory mediators needed to increase the expression of inducible NO synthase (iNOS), or by direct inhibitory effects of glucocorticoids on iNOS expression [35, 36]. The lack of effect on CA,NO during fluticasone treatment suggests either that there is no steroid-sensitive iNOS expression in small airways/lung parenchyma in COPD or that the deposition of fluticasone from a dry-powder inhaler is not sufficient in the lung periphery. A trial with systemic glucocorticoids could clarify this issue, as oral prednisone has been shown to decrease CA,NO in asthmatics on regular ICS treatment [37].

Only a minority of patients had significant improvement in lung function (increase in FEV1 $\geqslant 12 \%$ and $\geqslant 200 \mathrm{~mL}$ ) during the fluticasone treatment, but half of the subjects had significant decrease in symptoms. This may be related to differences in the underlying causes of impaired lung function and symptoms in COPD. Airway obstruction in COPD is caused mainly by irreversible structural changes that are not related to current inflammatory activity (small airway fibrosis and loss of alveolar attachments due to emphysema) [38], and to a lesser extent by inflammation-related factors like mucus secretion and mucosal oedema. However, cough and sputum production are affected by the current degree of inflammatory activity. This difference in causative factors between symptoms and impaired lung function may explain why the subjects were more responsive to fluticasone in terms of symptoms rather than of lung function, and why baseline inflammatory markers were able to predict better the effect of fluticasone on symptoms than on lung function. 
The higher the baseline $J^{\prime}$ aw,NO, the higher was the improvement in post-bronchodilator FEV1/FVC in ex-smokers. This suggests that high J'aw,NO is associated with steroid-sensitive large airway inflammation, the treatment of which improves lung function. However, the negative correlation between baseline $\mathrm{CA}, \mathrm{NO}$ and relative change in $\mathrm{FEF} 75 \%$ during fluticasone treatment (i.e. the higher the baseline $\mathrm{CA}, \mathrm{NO}$, the lower the improvement in $\mathrm{FEF} 75 \%$ ) is more difficult to interpret. One explanation might be that high CA,NO in COPD is not caused by a steroid-sensitive peripheral inflammation, but by irreversible structural changes. CA,NO can be increased either by increased peripheral NO production, or by decreased diffusing capacity of NO from alveolar air to pulmonary circulation (pathological changes in lung parenchyma or high ventilation to perfusion ratio) [12, 39]. Emphysema destroys pulmonary tissue available for gas transfer and thereby decreases pulmonary diffusing capacity of $\mathrm{NO}$ and could, in fact, also increase $\mathrm{CA}, \mathrm{NO}$. Thus, subjects with more pronounced emphysema might have higher $\mathrm{CA}$,NO because of decreased diffusing capacity of NO, but due to loss of alveolar attachments lower ability to improve small airway function during ICS treatment.

There are no previous intervention studies on the effect of ICS on these markers of inflammation in COPD, but our results are in line with the tendency towards lower bronchial NO output in steroid-treated COPD patients, as reported in a crosssectional study by BRINDICCI et al. [15]. Another cross-sectional study reported no difference in EBC levels of $\mathrm{LTB}_{4}$ in COPD patients treated or not with ICS [24], which is supported by our current finding of negative effect of fluticasone on EBC $\mathrm{LTB}_{4}$.

Smoking has been associated with decreased sensitivity to treatment with ICS in asthma and COPD [40]. In the current study, smokers tended to be less sensitive than ex-smokers for ICS in terms of lung function improvement, but there was no difference in symptom relief between current and ex-smokers. Furthermore, high $J^{\prime}$ aw,NO predicted symptom decrease in response to ICS in both current and ex-smokers, but its association with lung function improvement tended to be stronger in ex-smokers than in current smokers. Smoking might thus differently interfere with the various effects of glucocorticoids in COPD.

When assessing the role of exhaled NO measurement in COPD it is important to exclude asthma, as concomitant asthma with more eosinophilic and steroid-sensitive inflammation might bias the results. According to the GOLD guidelines, COPD is characterised by "airflow limitation that is not fully reversible" and COPD is diagnosed in subjects with relevant medical history based on a post-bronchodilator FEV1/FVC $<0.7$ [1]. Significant improvement ( $\geqslant 12 \%$ and $200 \mathrm{~mL}$ ) in FEV1 after administration of bronchodilators is no longer recommended for the differential diagnosis between asthma and COPD [1], as this test is not sensitive or specific enough [41]. Furthermore, in large clinical trials, more than half of the subjects with COPD show significant improvement in FEV1 following maximal bronchodilatation, even when asthma has been excluded [42]. We believe that all the subjects in the present study really had COPD, as none of them had a previous diagnosis or clinical history of asthma or significant diurnal variation in home peak expiratory flow monitoring, and they all had a smoking history $\geqslant 20$ pack-yrs and emphysema on HRCT. However, 17 of the 40 subjects had significant reversibility in FEV1 after administration of inhaled salbutamol, but there was no difference in baseline pulmonary function or any of the inflammatory measures between responders and nonresponders to salbutamol.

In conclusion, high pre-treatment levels of $J^{\prime}$ aw,NO are related to symptom relief and improvement of airway obstruction during treatment with inhaled fluticasone in COPD. Levels of 8-isoprostane, cysLTs and $\mathrm{LTB}_{4}$ in EBC are not related to steroid responsiveness in COPD.

\section{SUPPORT STATEMENT}

The study was supported by grants from Tampere Tuberculosis Foundation (Tampere, Finland), The Research Fund of Tampere University Hospital (Tampere), Väinö and Laina Kivi Foundation (Huittinen, Finland), Finnish Anti-Tuberculosis Association Foundation (Helsinki, Finland) and the Academy of Finland (Helsinki).

\section{STATEMENT OF INTEREST}

Statements of interest for L. Lehtimäki, H. Kankaanranta, S Saarelainen, E. Moilanen, and for the study itself can be found at www.erj.ersjournals.com $/ \mathrm{misc} /$ statements.dtl

\section{ACKNOWLEDGEMENTS}

The authors thank M-L. Lampén (University of Tampere, Tampere, Finland) and M. Soukkanen (Tampere University Hospital, Tampere) for technical help, H. Määttä (University of Tampere) for secretarial assistance, and GlaxoSmithKline (Espoo, Finland) for providing the study medication.

\section{REFERENCES}

1 Rabe KF, Hurd S, Anzueto A, et al. Global Initiative for Chronic Obstructive Lung DiseaseGlobal strategy for the diagnosis, management, and prevention of chronic obstructive pulmonary disease: GOLD executive summary. Am J Respir Crit Care Med 2007; 176: 532-555.

2 Fabbri LM, Romagnoli M, Corbetta L, et al. Differences in airway inflammation in patients with fixed airflow obstruction due to asthma or chronic obstructive pulmonary disease. Am J Respir Crit Care Med 2003; 167: 418-424.

3 Burge PS, Calverley PM, Jones PW, et al. Randomised, double blind, placebo controlled study of fluticasone propionate in patients with moderate to severe chronic obstructive pulmonary disease: the ISOLDE trial. BMJ 2000; 320: 1297-1303.

4 Smith AD, Cowan JO, Brassett KP, et al. Exhaled nitric oxide: a predictor of steroid response. Am J Respir Crit Care Med 2005; 172: 453-459.

5 Meijer RJ, Postma DS, Kauffman HF, et al. Accuracy of eosinophils and eosinophil cationic protein to predict steroid improvement in asthma. Clin Exp Allergy 2002; 32: 1096-1103.

6 Smith AD, Cowan JO, Brassett KP, et al. Use of exhaled nitric oxide measurements to guide treatment in chronic asthma. $N$ Engl J Med 2005; 352: 2163-2173.

7 Green RH, Brightling CE, McKenna S, et al. Asthma exacerbations and sputum eosinophil counts: a randomised controlled trial. Lancet 2002; 360: 1715-1721.

8 Brightling CE, Monteiro W, Ward R, et al. Sputum eosinophilia and short-term response to prednisolone in chronic obstructive pulmonary disease: a randomised controlled trial. Lancet 2000; 356: 1480-1485.

9 Brightling CE, McKenna S, Hargadon B, et al. Sputum eosinophilia and the short term response to inhaled mometasone in chronic obstructive pulmonary disease. Thorax 2005; 60: 193-198. 
10 Leigh R, Pizzichini MM, Morris MM, et al. Stable COPD: predicting benefit from high-dose inhaled corticosteroid treatment. Eur Respir J 2006; 27: 964-971.

11 American Thoracic Society, European Respiratory Society. ATS/ ERS recommendations for standardized procedures for the online and offline measurement of exhaled lower respiratory nitric oxide and nasal nitric oxide, 2005. Am J Respir Crit Care Med 2005; 171 : 912-930.

12 Tsoukias NM, George SC. A two-compartment model of pulmonary nitric oxide exchange dynamics. J Appl Physiol 1998; 85: 653-666.

13 Silkoff PE, Sylvester JT, Zamel N, et al. Airway nitric oxide diffusion in asthma: role in pulmonary function and bronchial responsiveness. Am J Respir Crit Care Med 2000; 161: 1218-1228.

14 George SC, Högman M, Permutt S, et al. Modeling pulmonary nitric oxide exchange. J Appl Physiol 2004; 96: 831-839.

15 Brindicci $\mathrm{C}$, Ito $\mathrm{K}$, Resta $\mathrm{O}$, et al. Exhaled nitric oxide from lung periphery is increased in COPD. Eur Respir J 2005; 26: 52-59.

16 Högman M, Holmkvist $\mathrm{T}$, Wegener $\mathrm{T}$, et al. Extended $\mathrm{NO}$ analysis applied to patients with COPD, allergic asthma and allergic rhinitis. Respir Med 2002; 96: 24-30.

17 Roy K, Borrill ZL, Starkey C, et al. Use of different exhaled nitric oxide multiple flow rate models in COPD. Eur Respir J 2007; 29: 651-659.

18 Martin TR, Pistorese BP, Chi EY, et al. Effects of leukotriene $B_{4}$ in the human lung. Recruitment of neutrophils into the alveolar spaces without a change in protein permeability. J Clin Invest 1989; 84: 1609-1619.

19 Montuschi P, Barnes PJ. Exhaled leukotrienes and prostaglandins in asthma. J Allergy Clin Immunol 2002; 109: 615-620.

20 Kostikas K, Gaga M, Papatheodorou G, et al. Leukotriene $B_{4}$ in exhaled breath condensate and sputum supernatant in patients with COPD and asthma. Chest 2005; 127: 1553-1559.

21 Kostikas K, Koutsokera A, Papiris S, et al. Exhaled breath condensate in patients with asthma: implications for application in clinical practice. Clin Exp Allergy 2008; 38: 557-565.

22 Zanconato S, Carraro S, Corradi M, et al. Leukotrienes and 8isoprostane in exhaled breath condensate of children with stable and unstable asthma. J Allergy Clin Immunol 2004; 113: 257-263.

23 Janssen LJ. Isoprostanes: an overview and putative roles in pulmonary pathophysiology. Am J Physiol Lung Cell Mol Physiol 2001; 280: L1067-L1082.

24 Montuschi P, Kharitonov SA, Ciabattoni G, et al. Exhaled leukotrienes and prostaglandins in COPD. Thorax 2003; 58: 585-588.

25 Lehtonen $\mathrm{H}$, Oksa $\mathrm{P}$, Lehtimäki L, et al. Increased alveolar nitric oxide concentration and high levels of leukotriene $\mathrm{B}_{4}$ and 8isoprostane in exhaled breath condensate in patients with asbestosis. Thorax 2007; 62: 602-607.

26 Method and measuring equipment for measuring nitric oxide concentration in exhaled air. US patent 6,733,463.
27 Lehtimäki L, Kankaanranta H, Saarelainen S, et al. Extended exhaled NO measurement differentiates between alveolar and bronchial inflammation. Am J Respir Crit Care Med 2001; 163: 15571561.

28 Condorelli $\mathrm{P}$, Shin HW, Aledia AS, et al. A simple technique to characterize proximal and peripheral nitric oxide exchange using constant flow exhalations and an axial diffusion model. J Appl Physiol 2007; 102: 417-425.

29 Jones PW, Quirk FH, Baveystock CM. The St George's Respiratory Questionnaire. Respir Med 1991; 85: Suppl. B, 25-31.

30 Suresh V, Shelley DA, Shin HW, et al. Effect of heterogeneous ventilation and nitric oxide production on exhaled nitric oxide profiles. J Appl Physiol 2008; 104: 1743-1752.

31 Brightling CE, Symon FA, Birring SS, et al. Comparison of airway immunopathology of eosinophilic bronchitis and asthma. Thorax 2003; 58: 528-532.

32 Payne DN, Adcock IM, Wilson NM, et al. Relationship between exhaled nitric oxide and mucosal eosinophilic inflammation in children with difficult asthma, after treatment with oral prednisolone. Am J Respir Crit Care Med 2001; 164: 1376-1381.

33 van den Toorn LM, Overbeek SE, de Jongste JC, et al. Airway inflammation is present during clinical remission of atopic asthma. Am J Respir Crit Care Med 2001; 164: 2107-2113.

34 Lehtimäki L, Kankaanranta H, Saarelainen S, et al. Inhaled fluticasone decreases bronchial but not alveolar nitric oxide output in asthma. Eur Respir J 2001; 18: 635-639.

35 Kleinert H, Euchenhofer C, Ihrig-Biedert I, et al. Glucocorticoids inhibit the induction of nitric oxide synthase II by downregulating cytokine-induced activity of transcription factor nuclear factor-kappa B. Mol Pharmacol 1996; 49: 15-21.

36 Korhonen R, Lahti A, Hämäläinen $\mathrm{M}$, et al. Dexamethasone inhibits inducible nitric-oxide synthase expression and nitric oxide production by destabilizing mRNA in lipopolysaccharide-treated macrophages. Mol Pharmacol 2002; 62: 698-704.

37 Gelb AF, Taylor CF, Nussbaum E, et al. Alveolar and airway sites of nitric oxide inflammation in treated asthma. Am J Respir Crit Care Med 2004; 170: 737-741.

38 Barnes PJ. Small airways in COPD. N Engl J Med 2004; 350: 26352637.

39 Hyde RW, Geigel EJ, Olszowka AJ, et al. Determination of production of nitric oxide by lower airways of humans - theory. J Appl Physiol 1997; 82: 1290-1296.

40 Adcock IM, Barnes PJ. Molecular mechanisms of corticosteroid resistance. Chest 2008; 134: 394-401.

41 Kesten S, Rebuck AS. Is the short-term response to inhaled betaadrenergic agonist sensitive or specific for distinguishing between asthma and COPD? Chest 1994; 105: 1042-1045.

42 Tashkin DP, Celli B, Decramer M, et al. Bronchodilator responsiveness in patients with COPD. Eur Respir J 2008; 31: 742-750. 